\title{
Applications of High and Ultra High Pressure Homogenization for Food Safety
}

\author{
Francesca Patrignani and Rosalba Lanciotti* \\ Department of Agricultural and Food Sciences, University of Bologna, Bologna, Italy
}

Traditionally, the shelf-life and safety of foods have been achieved by thermal processing. Low temperature long time and high temperature short time treatments are the most commonly used hurdles for the pasteurization of fluid foods and raw materials. However, the thermal treatments can reduce the product quality and freshness. Consequently, some non-thermal pasteurization process have been proposed during the last decades, including high hydrostatic pressure, pulsed electric field, ultrasound (US), and high pressure homogenization $(\mathrm{HPH})$. This last technique has been demonstrated to have a great potential to provide "fresh-like" products with prolonged shelf-life. Moreover, the recent developments in high-pressure-homogenization technology and the design of new homogenization valves able to withstand pressures up to 350-400 MPa have opened new opportunities to homogenization processing in the food industries and,

OPEN ACCESS

Edited by: Maria Schirone, University of Teramo, Italy

Reviewed by: Luca Settanni, University of Palermo, Italy Lucilla lacumin,

University of Udine, Italy

*Correspondence: Rosalba Lanciotti rosalba.lanciotti@unibo.it

Specialty section: This article was submitted to

Food Microbiology, a section of the journal Frontiers in Microbiology

Received: 23 March 2016 Accepted: 07 July 2016 Published: 03 August 2016

Citation: Patrignani Fand Lanciotti $R$ (2016) Applications of High and Ultra High Pressure Homogenization for Food Safety. Front. Microbiol. 7:1132. doi: 10.3389/fmicb.2016.01132 consequently, permitted the development of new products differentiated from traditional ones by sensory and structural characteristics or functional properties. For this, this review deals with the principal mechanisms of action of HPH against microorganisms of food concern in relation to the adopted homogenizer and process parameters. In addition, the effects of homogenization on foodborne pathogenic species inactivation in relation to the food matrix and food chemico-physical and process variables will be reviewed. Also the combined use of this alternative technology with other non-thermal technologies will be considered.

Keywords: high pressure homogenization, ultra high pressure homogenization, pathogenic species, inactivation, food matrices, non-thermal technologies, spores, enzymes

\section{INTRODUCTION}

For several decades, the food research has been focused on finding new solutions to old problems to ensure food safety without losing nutrients and more recently, in response to market demand, to preserve the sensory and the freshness of the products as well as to produce innovative foods, using safe, quick, economical, and environmental friendly processes (Zamora and Guamis, 2015). In a globalized market, the solution to these goals is fundamental for the survival of food and equipment enterprises, especially the small and medium enterprises (SMEs). The enterprise competition makes crucial the innovation in processes and products and user-friendly processes have been designed, focusing the interest on the application of new processing technologies including high pressure homogenization (HPH) and ultra high pressure homogenization (UHPH; Dumay et al., 2013). 
The word "homogenization" is referred to the ability to produce a homogeneous size distribution of particles suspended in a liquid, by forcing the liquid under the effect of pressure through a specifically designed homogenization valve. Homogenizer able to process fluid matrices at pressure ranging between $20-100 \mathrm{MPa}$ are nowadays employed in the dairy beverage, pharmaceutical, and cosmetic industries mainly to reduce particle size and consequently increase stability of emulsions in order to avoid creaming and coalescence phenomena (Figure 1). However, HPH was firstly employed as an useful method for cell disruption and recovery of intracellular bio-products (Keshavarz Moore et al., 1990; Shirgaonkar et al., 1998). The successful results obtained on cell disruption of dense microbial cultures stimulated researches on the application of $\mathrm{HPH}$ for food safety and shelf-life improvement. In fact, in the food industry, there is a growing interest in mild non-thermal processes, which combine an efficient microbial reduction with a maximal retention of physic-chemical product properties, as well as nutritional and sensory characteristics of the raw materials and ingredients used. Among the non-thermal treatments studied and proposed, $\mathrm{HPH}$ is regarded by a wide literature as one of the most encouraging alternatives to traditional heat treatments for food preservation and diversification dairy products, emulsions, egg based foods and fruit juices. Its effectiveness in the deactivation of spoilage microorganisms in model and real systems is well documented since 1994 (Lanciotti et al., 1994, 1996; Guerzoni et al., 1999; Kheadr et al., 2002; Wuytack et al., 2002; Vannini et al., 2004; Diels and Michiels, 2006; Bevilacqua et al., 2009; Patrignani et al., 2009a, 2010, 2013a,b; Zhao et al., 2014; Ferragut et al., 2015). However, HPH effectiveness for microbial inactivation is affected by several parameters such as process and microbial-physiological factors and aspects related to the characteristics of the treated fluid.

The HPH has been proposed also for the bacterial spore inactivation, generally in combination with other physicchemical hurdles for spore surviving and/or germination due to the ability of bacterial spores to survive to the most prohibitive conditions (Wuytack et al., 2002; Bevilacqua et al., 2007, 2012; Chaves-López et al., 2009; Chen et al., 2013; Roig-Sagues et al., 2015). In addition to the effects on microbial cells, the $\mathrm{HPH}$ treatment is reported to act on food constituents, especially proteins and enzymes, modifying their functional properties and activities (Kheadr et al., 2002; Hayes and Kelly, 2003; Vannini et al., 2004; Iucci et al., 2008; Navarro et al., 2014). In fact, it is reported to improve food microstructure, rheology and availability of food bioactive compounds (Guerzoni et al., 1997, 2002; Lanciotti et al., 2004a,b; Sandra and Dalgleish, 2005; Betoret et al., 2015). Moreover, it has been proposed as a useful tool to enhance the cheese yield and reduce the cheese ripening times due to the enhancement of proteolysis and lipolysis of milk naturally occurring or microbial enzymes (Guerzoni et al., 1999; Lanciotti et al., 2004b, 2006, 2007a; Burns et al., 2008; Vannini et al., 2008; Burns et al., 2015). Moreover, the effects of $\mathrm{HPH}$, applied at sub-lethal level (50 MPa), was studied on several strains of Lactobacillus spp., and particularly non-starter LAB (NSLAB), inoculated in milk as adjunct and involved in dairy product ripening (Lanciotti
Standardization of milk in terms of fat and proteins<smiles>C1=CCCCC1</smiles>

Milk Homogenization at $20 \mathrm{MPa}$<smiles>CCCCC</smiles>

Milk thermal treatment<smiles>C1=CCCCC1</smiles>

Inoculation of therm ophilic microbial cultures<smiles>C1=CCCCC1</smiles>

Fermentation at $42-45^{\circ} \mathrm{C}$<smiles>C1=CCCCC1</smiles>

Chilling and storage at $4^{\circ} \mathrm{C}$

FIGURE 1 | State of art of conventional homogenization in yoghurt preparation.

et al., 2007b). The literature data demonstrated that this cold technology is able to affect the strain metabolic activity and enzymes leading to a modification of the cheese ripening patterns, especially linked to the breakdown of proteins. The modification of enzyme and protein activity and functionality can greatly affect not only the food quality and ripening patterns but also the food safety feature due to the increased activities of egg and milk naturally occurring antimicrobials such as lysozyme, lactoperoxidase systems, and lactoferrin (Vannini et al., 2004; Iucci et al., 2007; Patrignani et al., 2013b) or reducing the biogenic amine content in cheeses obtained from HPH treated milk (Lanciotti et al., 2007a). In addition, $\mathrm{HPH}$ has been proposed with several roles in the functional food sector, for the production of probiotic dairy products with improved sensory or functional properties, such as probiotic strain viability over refrigerated storage and accelerated fermentation kinetics with less environmental impact with respect to the traditional heat treatment (Burns et al., 2008, 2015; Patrignani et al., 2009b, 2015a). In fact, sub-lethal pressure levels $(50 \mathrm{MPa})$ applied directly to microbial cells, increased some functional properties (i.e., hydrophobicity, resistance to simulated gastric conditions, and stomach-duodenum passage) in some probiotic strains associated to an increased maintenance of viability during refrigerated storage (Tabanelli et al., 2012, 2013, 2014). Also, Muramalla and Aryana (2011) reported low homogenization pressures (up to $13-80 \mathrm{MPa}$ for five passes) to improve certain probiotic characteristics of yogurt bacteria and Lactobacillus acidophilus LA-K (i.e., strain acid and bile tolerance) without effects on protease activity and strain growth potential. Additionally, these low homogenization pressure treatments, applied directly to probiotic strains, modified their interaction 
with the small intestines of BALB mice and induced a higher IgA response compared with untreated mice in a strain- and feeding period-dependent way (Tabanelli et al., 2012). Burns et al. (2015) studied the effects of a sub-lethal $\mathrm{HPH}$ on a probiotic strains used as adjunct for producing Caciotta cheese demonstrating that the $\mathrm{HPH}$-treated probiotic strain maintained high viability for 14 days whilst the physico-chemical analyses on Caciotta cheese containing HPH treated cells showed a faster ripening, compared to cheeses containing not $\mathrm{HPH}$ treated cells. In addition, these Authors demonstrated that the $50 \mathrm{MPa}$ treatment increased the L. paracasei gastric resistance in Caciotta, maintaining high strain viability without any significant effects on IgA production in mice.

The HPH technology has shown a great impulse both at industrial level and research field during the last decades also with the support of some important EU projects. The most relevant EU projects relative to the effects of $\mathrm{HPH}$ on food safety can be envisaged in the EU project HighQ RTE FP6FOOD-023140 "Innovative non-thermal processing technologies to improve the quality and safety of ready-to-eat (RTE) mealsHighQ RTE," EU Craft project “UHPH 512626, Development and Optimisation of a Continuous Ultra High Pressure Homogenizer for Application on Milks and Vegetable Milks" and the EU project FUNENTECH 232603 "study of functionality, nutritional and safety aspects of liquid foods, liquid food preparations, and cosmetics processed by ultrahigh-pressure homogenization". The last had the aim to reinforce transfer the HPH processing to SMEs of fluid or pumpable ingredients and foods as well as cosmetic sectors.

The research performed within national and international projects stimulated the improvement of the $\mathrm{HPH}$ equipments and devices and their adaptation to food processing lines. Several $\mathrm{HPH}$ equipments are nowadays available and some equipment producers, such as Microfluidics (USA), Bee International (USA), Avestin (Canada), Gea Niro Soavi (Italy), and APV (UK), have proposed pilot devices able to exert a pressure of 100$200 \mathrm{MPa}$, with average flow of $160 \mathrm{~L} / \mathrm{h}$ at $200 \mathrm{MPa}$ (Zamora and Guamis, 2015). However, Stansted Fluid Power Ltd (United Kingdom) have developed from the year 2006 pilot devices able to work up to $400 \mathrm{MPa}$ giving origin to the UHPH technology applied to food sector. Also Gea Niro Soavi (Italy) developed within the project made in Italy ATENA a pilot homogenizer able to work at $400 \mathrm{MPa}$, having an average flow of $5 \mathrm{~L} / \mathrm{h}$ (patent no. US-2015-0314254-A1, 11/05/2015). This prototype was used to obtained apple and tomato based formulations having a shelf-life of 30 days when stored at environmental temperature and treated at 300-400 MPa. At the expire date the levels of Listeria monocytogenes, Escherichia coli, Staphylococcus aureus, Bacillus cereus and Salmonella spp. were under the detection limits even in the samples inoculated before the HPH treatments at levels ranging between 3 and 4 log $\mathrm{CFU} / \mathrm{ml}$.

Since the safety features are prerequisite both for traditional and innovative products, this review is focused on the effects of $\mathrm{HPH}$ on foodborne pathogen inactivation in relation to the food matrix and food physico-chemical and process variables. Moreover, the review takes into consideration also the opportunity to inactivate the spores from pathogenic bacteria by using dynamic pressure. Also the potential of $\mathrm{HPH}$ to increase the activity of antimicrobial enzymes to inactivate pathogenic microorganism will be taken into consideration. Finally, the combined use of this alternative technology with other non-thermal technologies will be considered within this review.

\section{MECHANISM OF ACTION OF HIGH PRESSURE HOMOGENIZATION}

From a technological point of view, an homogenizer consists principally of a pump and a homogenizing valve (Figure 2). The pump is used to force the fluid into the valve where the homogenization happens (Diels and Michiels, 2006). In the homogenizing valve the fluid is forced under pressure through a small orifice between the valve and the valve seat. The operating pressure is controlled by adjusting the distance between the valve and the seat. Among the process parameters, the level of pressure applied and the temperature reached in the food matrix during the process are the variables able to affect the food components and the eventually occurring microbial cells. The microbial inactivation caused by the application of $\mathrm{HPH}$, although affected by several factors and mainly by the physic chemical features of the food matrix and the sensitiveness of different microorganisms, increases with the pressure level (Diels and Michiels, 2006). The effects induced by the temperature have to be necessarily taken into account in $\mathrm{HPH}$, since, during homogenization, a rise of the temperature (about $2.5^{\circ} \mathrm{C}$ per $10 \mathrm{MPa})$, related to the fluid food employed, is observed in the fluid downstream of the valve. This is generally attributed by the literature to the viscous stresses caused by the high velocity of the fluid flow, which is then impinging on the ceramic valve of the homogenizer, leading to the dissipation of a significant fraction of the mechanical energy as heat in the fluid (Floury et al., 2000; Zamora and Guamis, 2015). However, such temperature increase did not result in the appearance of heat indicators in $\mathrm{HPH}$ treated food samples probably due the flash time of treatment of the food matrices (lower than 1 s; Floury et al., 2004; Pinho et al., 2011). For example HPH treated milk samples suffered less Maillard reaction, less whey protein denaturation and did not present lactose isomerisation compared to a commercial pasteurized milk with a concomitant preservation of essential amino acids and as a consequence with a better nutritional value desired by consumers (Pereda et al., 2009).

The significant improvement of HPH equipment functionality and flexibility (capacity to work in a food processing line), the design of new valves able to work at 300-400 $\mathrm{MPa}$ and the significant research efforts make $\mathrm{HPH}$ technology ready for the scaling up at industrial level for the development of new products differentiated from traditional ones by sensory and structural characteristics or functional properties. Also patents regarding continuous systems and procedure of sterilization and physical stabilization of pumpable fluids by means of $\mathrm{HPH}$ are available (i.e., EP 2409583 A1). 


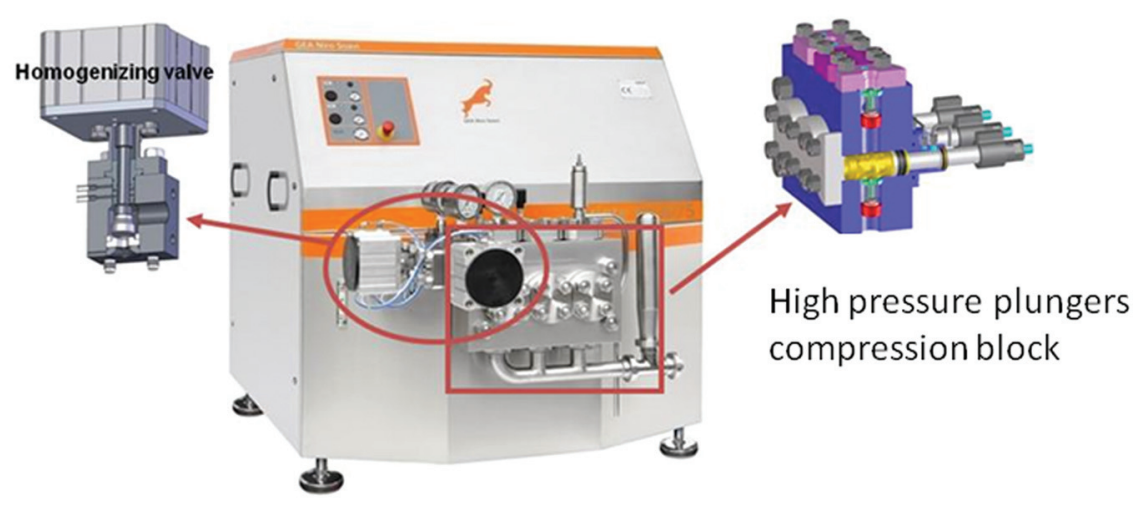

FIGURE 2 | State of the art of homogenizer able to reach 200 MPa (GEA Niro Soavi, Italy).

\section{POTENTIAL AND APPLICATIONS OF HIGH AND ULTRA HIGH PRESSURE HOMOGENIZATION FOR PATHOGENIC SPECIES INACTIVATION IN VITRO AND FOOD SYSTEMS}

The first application of homogenization for the stabilization of food and dairy emulsion was presented at the Paris World's Fair in 1900 where Auguste Gaulin presented an invention for "intimately mixing milk" using pressures up to $30 \mathrm{MPa}$ (Gaulin, 1899). Since then conventional homogenization extended the pressure range until $50 \mathrm{MPa}$. $\mathrm{HPH}$, also known as dynamic $\mathrm{HPH}$, has been frequently highlighted for its potential for food cold pasteurization (Diels and Michiels, 2006; Donsì et al., 2009a,b,c; Patrignani et al., 2009a, 2010, 2013a,b; Pereda et al., 2009; Panozzo et al., 2014). Modern high pressure homogenizer enables pressures 10-15 times higher than traditional ones and covers pressure ranges between 300 and $400 \mathrm{MPa}$. These last ranges have been referred to as UHPH. The progression toward UHPH has also opened the view to new sterilization opportunities, including also the inactivation of spores by HPH. The inlet temperature of pumpable products and the level of pressure, which both determine the temperature reached during the UHPH treatment, have been considered as the main factors of the microbial inactivation (Zamora and Guamis, 2015). UHPH warrants the destruction of microorganisms reaching sterilization of liquid food products, and it has a positive influence on food stability, with few effects on nutritional value and sensory characteristics of the processed fluids. UHPH technology allows more efficient particle reduction than the classical homogenization, and its effect is the results of several mechanisms such as sudden pressure drop, torsion and shear stresses, turbulence, impingement, cavitation phenomena, shock waves, and temperature increase, with a concomitant reduction of microbial load and interesting consequences in emulsion properties (Figure 3). Since its first appearance, HPH and, later, UHPH have been tested on several matrixes and in vitro systems by using different microbial targets to demonstrate their effectiveness. The microbial targets deal with pathogenic and spoilage microorganisms but in this review only the researches regarding the pathogenic species will be reviewed.

In Table 1, the studies regarding the microbial inactivation in model systems by HPH or UHPH, in relation to the microbial targets, inoculation level and conditions adopted, are reported.

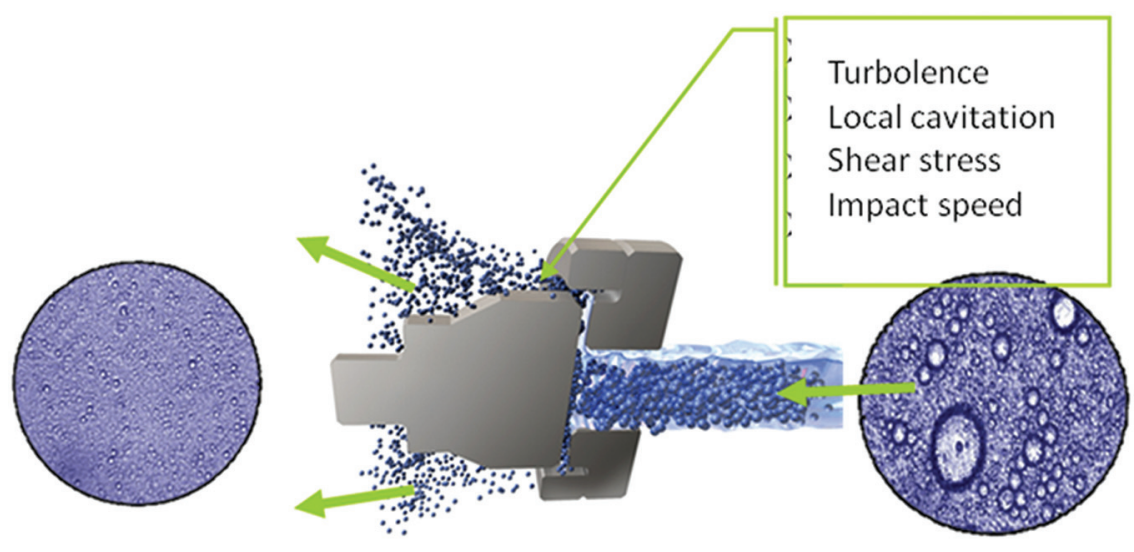

FIGURE 3 | Most probable mechanisms of action of HPH (GEA Niro Soavi, Italy). 
TABLE 1 | High pressure homogenization (HPH) microbial inactivation in relation to the model system, species and process conditions adopted.

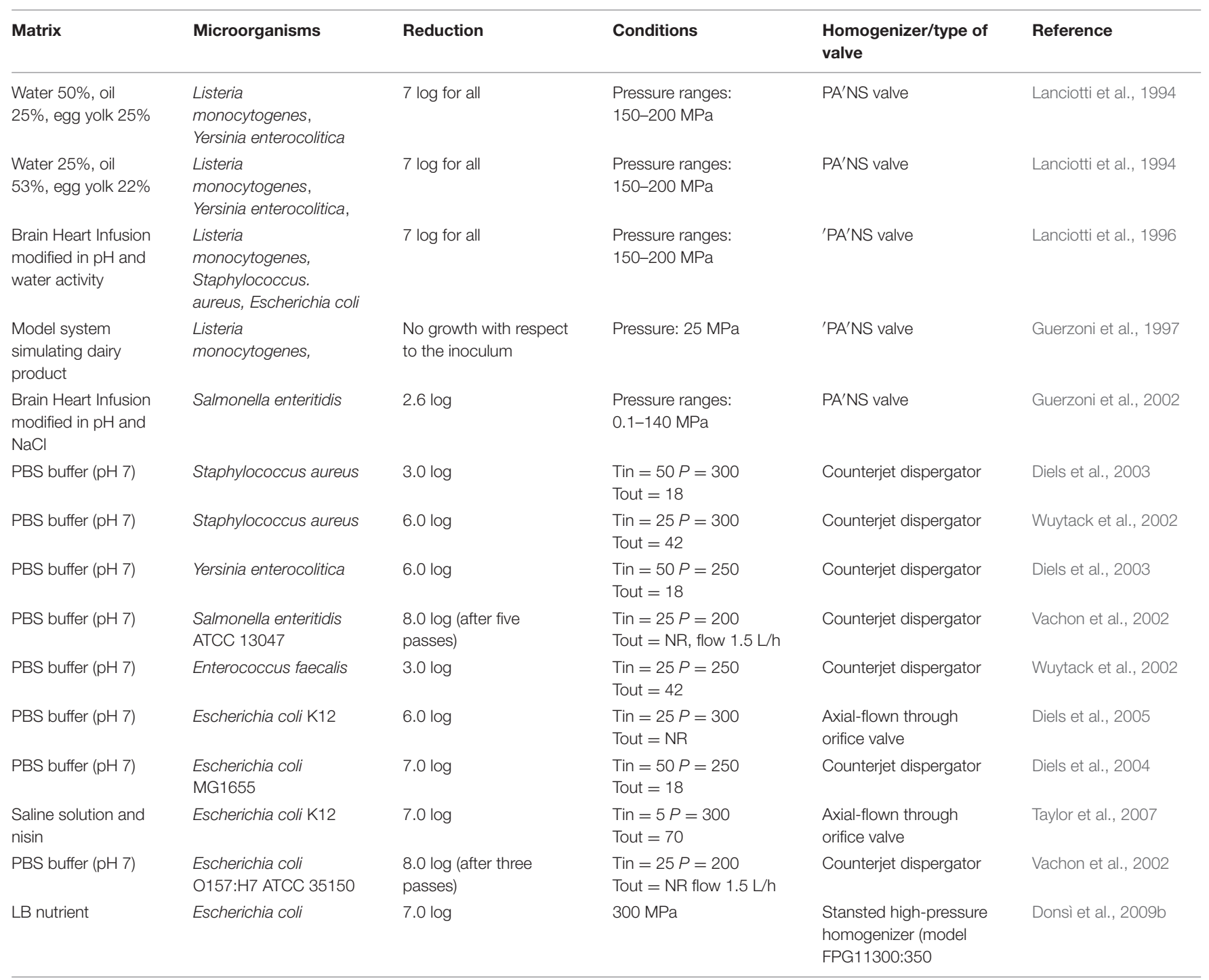

Lanciotti et al. (1994) studied the effectiveness of pressures ranging from 15 to $200 \mathrm{MPa}$, applied with a continuous homogenizer (Niro Soavi, Parma, Italy), on the cell viability of spoilage and pathogenic microorganisms in two model systems made of water $50 \%$, oil $25 \%$, egg yolk $25 \%$, the first, and water $25 \%$, oil 53\%, egg yolk 22\%, the second. Moreover, the effects of microstructural modifications of food systems associated with the treatments on cell viability and on its subsequent evolution were investigated. Modulation of the homogenization pressure allowed strong instantaneous reductions of the initial cell loads of L. monocytogenes and Yersinia enterocolitica. The combined effects of the initial pressure treatment and space reduction, resulting from the microstructural modifications of food systems, increased the safety and the shelf-life both of water in oil and oil in water emulsions. Moreover, Lanciotti et al. (1996) investigated also the effects of chemico-physical growth conditions such as $\mathrm{pH}$, temperature and water activity (a) on lethal high homogenization pressure effects on L. monocytogenes,
S. aureus, and E. coli. The results, based on standard medium such as Brain Heart Infusion (BHI), highlighted the importance of food system composition and its thermal history on the high pressure tolerance of the microbial population. In previous work, Lanciotti et al. (1994) showed that the relationship between survival cells and instantaneous pressure applied in medium appeared to be log-linear in a range between 40 and $200 \mathrm{MPa}$. According to the author findings, $S$. aureus was the most resistant pathogenic species while L. monocytogenes was resistant to pressure only when grown at highest aw. Also Guerzoni et al. (1997) studied the growth of L. monocytogenes in a model system, simulating a dairy product, when treated at $25 \mathrm{MPa}$, in relation to the lipid content $\mathrm{NaCl}$ and $\mathrm{pH}$ values, modulated according to a Central Composite Design (CCD). Polynomial equations describing the effects of such variables on the aw, microstructural features, and L. monocytogenes growth, were obtained. The three variables and their interactions, in addition to a direct effect on microbial growth, played an indirect role 
due to their influence on microstructural features, such as diameter of water droplets and total water phase availability. In particular, the $\mathrm{pH}$ value affected the $\mathrm{a}(\mathrm{w})$ and the total space available for microbial growth, while the $\mathrm{NaCl}$ content had a prevalently indirect effect on space availability and on the diameter of the water droplets. The results suggested that the microstructural changes induced by $\mathrm{HPH}$ affected the growth of L. monocytogenes which was dependent on the total water phase space availability. Guerzoni et al. (2002) studied the survival of Salmonella enteritidis after pressure treatments, ranging between 0.1 and $140 \mathrm{MPa}$, in relation to compositive variables $(\mathrm{NaCl}$ content, $\mathrm{pH}$ ). The study was performed both in model (BHI) and real systems consisting of an egg-based mayonnaise type product. Moreover, the fate of the surviving cells of $S$. enteritidis was monitored during storage at $10^{\circ} \mathrm{C}$ and the growth or death parameters were calculated and modeled in relation to $\mathrm{pH}, \mathrm{NaCl}$ concentration of the medium and the level of pressure treatment applied. From this study, it was evident that the salt content and $\mathrm{pH}$ displayed a synergistic effect with pressure, whose extent was higher in the mayonnaise based products than in BHI. In fact, while in the model systems the cell recovery and growth during the subsequent incubation at $10^{\circ} \mathrm{C}$ was allowed in many combinations of the CCD, in the real systems no recovery or growth of $S$. enteritidis were observed. According to the Authors, this viability loss, which was maximum at $\mathrm{pH} 4.00$ or $2 \% \mathrm{NaCl}$, is not be attributed merely to the interactions of such variables, but it probably involved the naturally occurring antimicrobial enzymes of the raw material, whose activity can be enhanced by the pressure treatment. Reviewing the literature, one of the most studied in vitro system is represented by PBS buffer. Different Authors have investigated in this medium the potentialities of $\mathrm{HPH}$ treatment in pathogenic species inactivation. For example, Vachon et al. (2002) studied the effect of an homogenization treatment performed at $200 \mathrm{MPa}$, repeated for five cycles, on the inactivation of $S$. enteritidis ATCC 13047, E. coli O157:H7 ATCC35150 and L. monocytogenes LSD 105-1 when inoculated in PBS buffer at $\mathrm{pH}$ 7. The results showed that E. coli and L. monocytogenes reached $8 \mathrm{log}$ reduction cycles after the $\mathrm{HPH}$ treatment after three passes while five passes were necessary to reach the same inactivation level for $S$. enteritidis. Also Wuytack et al. (2002) found that a treatment of $300 \mathrm{MPa}$ was able to inactivate $S$. aureus, Enterococcus faecalis and L. innocua of 6, 3, and $5 \log$ reduction cycles in $\mathrm{PBS}$ buffer $\mathrm{pH} 7$, using a treatment of $300 \mathrm{MPa}$ and a fluid inlet temperature of $25^{\circ} \mathrm{C}$. Diels et al. (2003) conduced a detailed study of the inactivation of $S$. aureus and $Y$. enterocolitica in PBS buffer by $\mathrm{HPH}$ at, respectively, 25 and 35 different combinations of process temperature and process pressure covering a range of $5-50^{\circ} \mathrm{C}$ and $100-300 \mathrm{MPa}$. In the entire studied, it was clear that $S$. aureus was more resistant to $\mathrm{HPH}$ than $Y$. enterocolitica, as already demonstrated by Lanciotti et al. (1996). Also, temperature between 5 and $40^{\circ} \mathrm{C}$ did not affect inactivation of $S$. aureus by high-pressure homogenisation, while $Y$. enterocolitica inactivation was affected by temperature over a much wider range. Later, Diels et al. (2005) investigated the resistance of E. coli K12 when treated in PBS buffer at $300 \mathrm{MPa}$ by using a axial-flow through orifice valve, outlining reduction of $6 \log$ cycles. Donsi et al. (2009c) studied the inactivation of E. coli by HPH in model systems, under a wide range of operating conditions (temperature, pressure, number of homogenization passes, cell concentration) in a lab-scale and a pilot-scale unit (Stansted Fluid Power) utilizing single or multiple passes. Results highlighted that the inactivation kinetics did not depend linearly on pressure, due to the distribution of individual cell resistance in the sample. The efficacy of the treatment at higher pressures or upon multiple passes was reduced. Moreover, the scale of the apparatus, which in this case differed of several order of magnitude (from 0.7 to $120 \mathrm{l} / \mathrm{h}$ ), and consequently of the width of the gap of the valve did not affect the extent of microbial inactivation at a given pressure. Taylor et al. (2007) studied the inactivation of E. coli K-12 cells, grown statically or in chemostat, when exposed to $\mathrm{HPH}$ processing pressures of 50 to $350 \mathrm{MPa}$ in the absence or presence of the antimicrobial nisin. These Authors found that pressure and temperature exhibited a quadratic relationship. Significant HPH-induced inactivations of the Gram-negative microorganism was observed in the range of 100 to $250 \mathrm{MPa}$. Above $300 \mathrm{MPa}$, heat was the main factor promoting microbial inactivation, regardless of whether cells were grown in chemostat or statically. Chemostat-grown cells were significantly more resistant to $\mathrm{HPH}$ processing than were statically grown cells. Moreover, the data indicated a potential synergistic effects of nisin and HPH on the inactivation of bacterial contaminants, although this antimicrobial is generally active against Grampositive bacteria.

However, although a huge amount of data collected from model systems were available and helpful to understand the mechanisms of action of HPH against pathogenic species, many researchers tested potentialities of this technology against pathogenic species inoculated in food matrixes because the composition and viscosity of the treated food also have an indirect effect on the microbial inactivation (Table 2). The available literature reports about the use of $\mathrm{HPH}$ for the reduction of foodborne pathogens in several food matrices, such as milk (Lanciotti et al., 1994; Diels et al., 2005; Hayes et al., 2005; Brinez et al., 2006a,b, 2007; López-Pedemonte et al., 2006; RoigSagues et al., 2009), egg-based products (Velazquez-Estrada et al., 2008; Patrignani et al., 2013b), orange juice (Brinez et al., 2006b; Kumar et al., 2009; Pathanibul et al., 2009; Maresca et al., 2011), mayonnaise type products (Guerzoni et al., 2002). Lanciotti et al. (1994) found that the relationship between surviving cells and pressure applied was log-linear in milk inoculated with $Y$. enterocolitica and L. monocytogenes and processed at different pressures $(40-150 \mathrm{MPa})$ at $25^{\circ} \mathrm{C}$. In order to establish the fate of the surviving cells, the growth of $Y$. enterocolitica, and L. monocytogenes, in the samples stored at $3-4^{\circ} \mathrm{C}$, was followed over $220 \mathrm{~h}$. The data were analyzed according to the Gompertz equation. For Y. enterocolitica and L. monocytogenes, the treatment apparently did not induce irreversible damage to the surviving cells; in fact, although the lag phase was prolonged when pressures higher than 400 bar were used, the $\mu$ max increased with the applied pressure and the maximal cell numbers attained $(\mathrm{A}+\mathrm{K})$ were independent on the level of the applied pressure. Diels et al. (2005) studied the inactivation of E. coli MG1655 in skim, soy and strawberry-raspberry milk 
TABLE 2 | High pressure homogenization microbial inactivation in relation to the food matrix, species and process conditions adopted.

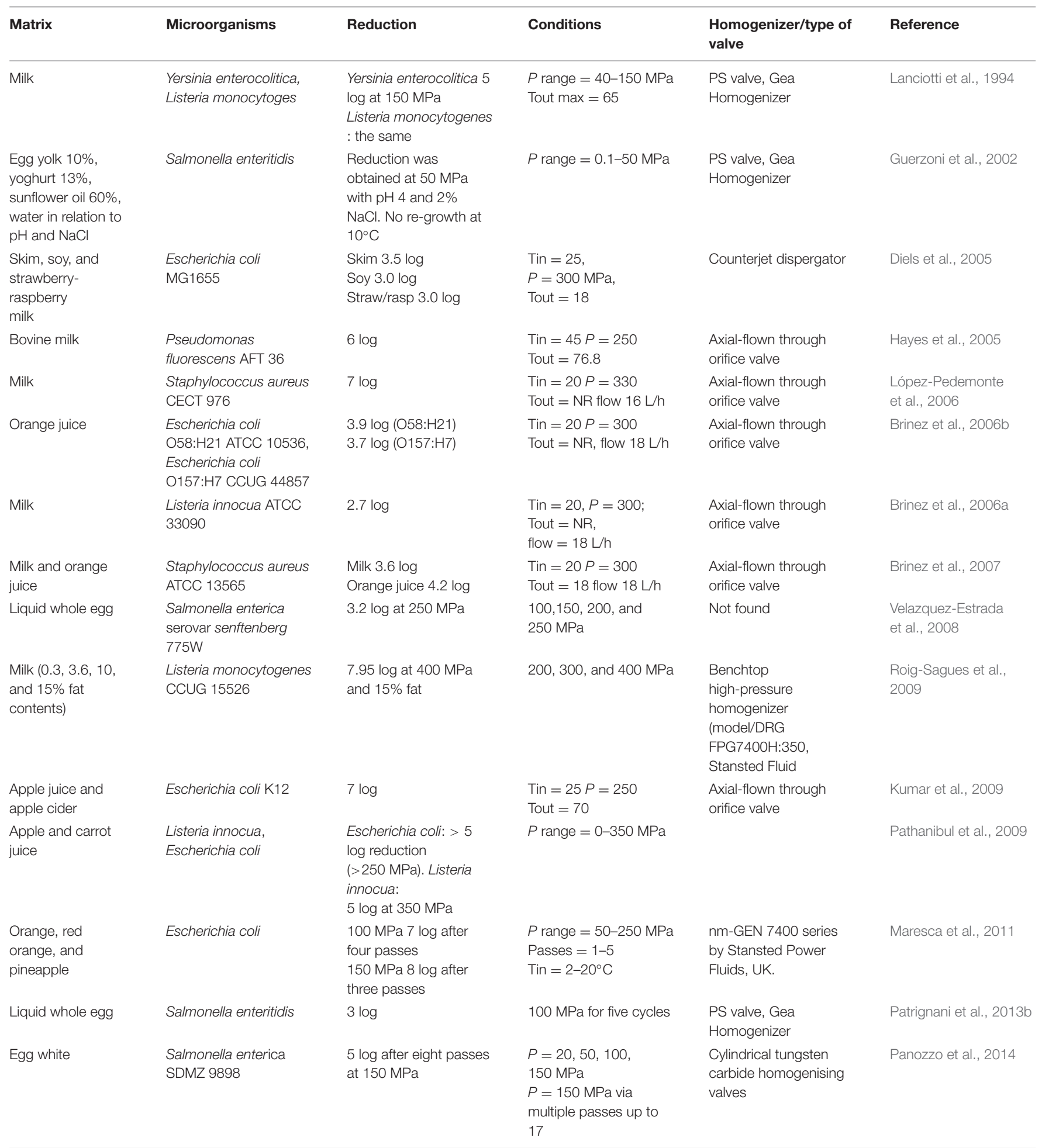

subjected to $300 \mathrm{MPa}$ founding that the highest inactivation was reached in skim milk with a Tin and Tout temperature of 25 and $18^{\circ} \mathrm{C}$, respectively, by using a counterjet dispergator valve. Hayes et al. (2005), utilizing an axial-flown through orifice valve, found in milk treated at $250 \mathrm{MPa}$, with a Tin of $45^{\circ} \mathrm{C}$ and a
Tout of 76.8, a 6 log reduction of Pseudomonas fluorescens AFT 36 , resulting from the application of pressure and temperature increase. Lowest reduction (2.7 $\log$ ) was found by Brinez et al. (2006b) for L. innocua ATCC33090 in bovine milk or S. aureus ATCC 13565 (3.6 log reduction) and S. aureus CECT 4491 in 
milk (Brinez et al., 2007). López-Pedemonte et al. (2006) found high inactivation for $S$. aureus CECT 976 inoculated in milk treated at $330 \mathrm{MPa}$. Roig-Sagues et al. (2009) reported about the inactivation of L. monocytogenes CCUG 15526 when inoculated at $7.0 \log \mathrm{CFU} / \mathrm{ml}$ in milk samples having $0.3,3.6,10$, and $15 \%$ of fat contents. The samples were subjected to a single cycle of UHPH treatment at 200,300, and $400 \mathrm{MPa}$. Microbiological analyses were performed $2 \mathrm{~h}$ after the UHPH treatments and after 5,8 , and 15 days of storage at $4^{\circ} \mathrm{C}$. Maximum lethality values were observed in samples treated at $400 \mathrm{MPa}$ with 15 and $10 \%$ fat $(7.95$ and $7.46 \log \mathrm{CFU} / \mathrm{ml})$, respectively, while in skimmed and $3.6 \%$ fat milk samples, complete inactivation was not achieved and, during the subsequent 15 days of storage at $4^{\circ} \mathrm{C}, \mathrm{L}$. monocytogenes was able to recover. In milk samples with 10 and $15 \%$ fat, L. monocytogenes recovered to the level of initial counts only in the milk samples treated at $200 \mathrm{MPa}$ but not in the milk samples treated at 300 and $400 \mathrm{MPa}$. According to these data, fat content increase enhanced the maximum temperature reached during UHPH treatment and this could have contributed to the lethal effect achieved. In addition the $\mathrm{HPH}$ treatments of milk is reported to enhance the release of free fatty acids (due to the rupture of fatty globule membranes and the activation of lipases), and mainly short and medium chain ones, having an antimicrobial effects (Lanciotti et al., 2006; Vannini et al., 2008). On the contrary, some Authors attributed to the fat content in milk a protective role against microbial species during the high pressure treatment performed at $100 \mathrm{MPa}$ for several cycles. Although several Authors have tested the same matrixes, and in some case the same microbial species, different inactivation results was achieved, particularly using the multi-pass approach. For example, Patrignani et al. (2013b) found that Salmonella inactivation in eggs, resulting from the application of $\mathrm{HPH}$ at $100 \mathrm{MPa}$, seems to be linearly correlated to the number of passes. This result, although using a different substrate and microorganism, is in agreement with the findings of Patrignani et al. (2010) who demonstrated for the spoiling Zygosaccharomyces bailii, inoculated in apricot and carrot juice, that the effect of each pass is additive and, therefore, each homogenization pass causes almost the same reduction of the microbial load. Several other authors have also found first order inactivation kinetics as a function of the number of passes (Wuytack et al., 2002; Diels and Michiels, 2006; Tahiri et al., 2006), although the literature data concerning the inactivation kinetics by HPH are still conflicting. In fact, Donsì et al. (2009c) observed that $\mathrm{HPH}$ inactivation of $E$. coli, produced a nonadditive trend for multiple pass processes at a given pressure level. These Authors attributed this behavior mainly to the physiological diversity within a microbial population and to the existence of resistant cells able to survive after repeated passes at the pressure applied. On the other hand, it is important to take into consideration the additional effect of $\mathrm{HPH}$ on the antimicrobial activity of naturally occurring enzymes, such as lysozyme, lactoperoxidase system and so on. VelazquezEstrada et al. (2008) have published data regarding the use of $\mathrm{HPH}$ for Salmonella inactivation in liquid whole egg (LWE). In particular, these Authors proposed the single-pass treatment of inoculated LWE with ultra HPH at 100, 150, 200, and
$250 \mathrm{MPa}$, demonstrating that the level of pressure applied can influence the $S$. enterica lethality attained. Moreover, Panozzo et al. (2014) outlined the potentialities of HPH as a promising alternative to thermal pasteurization of eggwhite. These Authors showed that a $\mathrm{HPH}$ at $150 \mathrm{MPa}$ for multiple passes was able to decontaminate egg white inoculated with S. enterica SDMZ 9898.

Many applications of HPH or UHPH for inactivation of spoiling and pathogenic species were tested in juices and vegetable drinks, where $\mathrm{HPH}$ and $\mathrm{UHPH}$ find a great application potential. For example, Brinez et al. (2006a) tested the inactivation of E. coli 058:H21 ATCC 10536 and E. coli 0157:H7 CCUG 44857 inoculated in orange juice and treated at $300 \mathrm{MPa}$ founding a $\log$ reduction of 3.9 and 3.7, respectively. Kumar et al. (2009) investigated on the inactivation of E. coli $\mathrm{K} 12$ in apple juice and apple cider obtaining an inactivation of 7 log applying a pressure of $250 \mathrm{MPa}$ with a Tin of $25^{\circ} \mathrm{C}$ and Tout of $70^{\circ} \mathrm{C}$, thus avoiding the use of a thermal exchanger. Also Pathanibul et al. (2009) inoculated L. innocua ATCC51742 and E. coli, as surrogate for foodborne pathogens, in apple and carrot juice, containing or not nisin (0-10 IU), and treated from 0.1 to $350 \mathrm{MPa}$. At $50 \mathrm{MPa}$ homogenization pressure intervals, juice samples were collected, immediately cooled to $10^{\circ} \mathrm{C}$, and then serially diluted and plated on non-selective recovery media. As processing pressure increased, inactivation of $E$. coli increased, and a 5 log reduction of cells was achieved following exposure to pressures in excess $250 \mathrm{MPa}$. In contrast, little inactivation was observed for L. innocua with pressures ranging between 250 and $350 \mathrm{MPa}$. However, several authors have been demonstrated the major efficacy of HPH against Gramnegative bacteria. The addition of $10 \mathrm{IU}$ nisin, together with $\mathrm{HPH}$, did not exhibit significant additional E. coli inactivation, but interactions were observed with L. innocua. On the other hand nisin is reported to be active against Gram-positive bacteria (Siroli et al., 2015).

\section{POTENTIAL AND APPLICATION OF HIGH PRESSURE HOMOGENIZATION FOR SPORE INACTIVATION IN VITRO AND FOOD SYSTEMS}

Bacterial spores represent one of the major hazard in food safety due to their high resistance to most hurdles. In particular, they are resistant to elevated temperatures $\left(80^{\circ} \mathrm{C}\right)$, which distinguishes them from vegetative cells. Thermal sterilization is the method to eliminate spores in most food applications, as it provides the highest guarantee of sterility. From a safety point of view, spores of Bacillus spp. and Clostridium spp. are greatly resistant to several treatment such as heat, desiccation, lack of nutrients, exposure to UV and gamma radiation, organic chemicals, and oxidizing agents. In general, the heat resistance of spores depends on conditions such as elevated sporulation temperature, the presence of minerals and dipicolinic acid (DPA), and core dehydration. The endospores are composed of a central core, which is surrounded by several protective layers. The outermost 
layer, the exosporium, is not present in spores of all species, and is the primary site of contact with the environment. Between the outer and inner membrane, there is the cortex. Since the spore structure plays a major role in spore resistance, the spore inactivation in foods requires high levels of heat treatments, which can in turn have negative effects on the sensory and nutritional profile (Schubert and Beaudet, 2011; Reineke et al., 2013; Georget et al., 2014a,b; Dong et al., 2015). For this reason, alternative and convenient methods have been studied in recent years (Chaves-López et al., 2009). In order to increase antimicrobial effectiveness and reduce side effects on food quality, the application of combined hurdles has also received great attention. Extensive literature indicates that the effects of combined stresses on microbial growth and survival may be additive or synergistic, when the outcome is usually significantly greater than the additive response (Tapia de Daza et al., 1996; Leistner, 2000; Ross et al., 2003), because of the disturbing action on microbial homeostasis in several respects (Leistner, 2000).

Because of its great potential for microbial inactivation, several authors have studied the effects of $\mathrm{HPH}$ or UHPH, when applied individually or in combination with other mild physical or chemical stresses (heat and $\mathrm{H}_{2} \mathrm{O}_{2}$ ), on the inactivation of Bacillus and Clostridium spores, whose genera, from a safety point of view, the most important species belong. The analysis of the literature shows that the major application for $\mathrm{HPH}$ and $\mathrm{UHPH}$ regards the inactivation of spores of spoiling bacteria while the reports dealing with the inactivation of spores from pathogenic species are sporadic. Focusing on pathogenic species, Chaves-López et al. (2009) evaluated the influence of HPH treatment, applied individually (one, two, or three cycles) or in combination with other mild physical or chemical stresses (mild heat treatment, $\mathrm{H}_{2} \mathrm{O}_{2}$, and low $\mathrm{pH}$ ), on the capability of $B$. cereus and $B$. subtilis spore, suspended in sterilized double distilled water, to form colonies. These Author determined also the effects of the treatments applied on the release of DPA from the spores, since spore resistance to stresses such as temperature and pressure has been correlated to their ability to retain DPA, present in the core region of the dormant spores (Setlow, 2000; Cortezzo et al., 2004). The Authors outlined how the application of specific stress sequences can significantly inactivate $B$. cereus spores. The remarkable efficacy of repeated cycles at $150 \mathrm{MPa}$ suggested that dynamic high pressure, particularly applied in combination with other sub-lethal stresses, could be a useful and innovative tool for $B$. cereus control in fluid foods. In particular, the Authors showed that, although plate count only slightly decreased in all the strains when one cycle of $\mathrm{HPH}$ at $150 \mathrm{MPa}$ was applied alone, the spores released significant levels of DPA (up to 28\%) that could indicate a possible disruption of spore layers. Three consecutive cycles of $\mathrm{HPH}$ determined high reduction of colony count (about 5 $\log \mathrm{CFU} / \mathrm{ml}$ ) and high DPA release (52\%). Among the stress conditions applied, it was observed that only the thermal shock after one $\mathrm{HPH}$ cycle reduced the colony count of $2.3 \mathrm{log}$ $\mathrm{CFU} / \mathrm{ml}$ and induced a DPA release up to $57 \%$. Pinho et al. (2011) evaluated the inactivation of Clostridium sporogenes PA 3679 spores (considered as harmless twin of C. botulinum) by $\mathrm{HPH}$ in model system such as skim milk, showing that that pressures up to $300 \mathrm{MPa}$ were not able to cause any reduction on spore counts or promote changes on their thermal resistance. The application of heat shock $\left(100^{\circ} \mathrm{C} / 15 \mathrm{~min}\right)$ before $\mathrm{HPH}$ treatment and the homogenization process realized at mild inlet temperature $\left(45^{\circ} \mathrm{C}\right)$, which results in homogenization temperature of around $84^{\circ} \mathrm{C}$ at $300 \mathrm{MPa}$, also did not cause reduction on viable spores counts. A few spores reduction (0.67 logarithmic cycles) were only observed when the milk samples were subjected to homogenization treatment for 16 cycles (multiple passes) at $300 \mathrm{MPa}$. Therefore, although $\mathrm{HPH}$ be recognized as an effective method for milk pasteurization, in this specific case, $\mathrm{HPH}$ process is not able to guarantee the commercial sterility of milk, being necessary the association of the homogenization with another preservative method, as refrigeration.

Also Amador Espejo et al. (2014) tested the ability of Ultra High-Pressure Homogenization treatments at $300 \mathrm{MPa}$ with inlet temperatures of $55,65,75$, and $85^{\circ} \mathrm{C}$ to inactivate $B$. cereus spores inoculated into commercial ultra high temperature treated whole milk in order to evaluate the inactivation level achieved. These Authors provided important evidence of the suitability of UHPH technology for the inactivation of spores in high numbers, leading to the possibility of obtaining commercially sterile milk. In fact, UHPH conditions at $300 \mathrm{MPa}$ with a inlet temperature of 75 and $85^{\circ} \mathrm{C}$ were capable of a spore inactivation of $5 \mathrm{log} \mathrm{CFU} / \mathrm{ml}$. Furthermore, under these processing conditions, commercial sterility (evaluated as the complete inactivation of the inoculated spores) was obtained in milk treated at $300 \mathrm{MPa}$ with inlet temperature of $75^{\circ} \mathrm{C}$.

\section{POTENTIAL OF HIGH PRESSURE HOMOGENIZATION TO INCREASE THE ANTIMICROBIAL ACTIVITY OF ENZYME OF FOOD INTEREST}

Because of the great interest within the food industry in aldehydes, ketones, esters as natural antimicrobial compounds (Burt, 2004; Patrignani et al., 2015b) or enzymes such as lysozyme, lactoperoxidase system and lactoferrin, many Authors have tried to find strategies to enhance their efficacy in foods. In general, the approaches used are aimed to destabilize the microbial outer membranes of Gram-negative bacteria or to modify the chemical structure of the enzyme. For example, Ibrahim et al. (1993) and Bernkop-Schnurch et al. (1998) showed that the antimicrobial spectrum of lysozyme can be extended, including also Gram-negative bacteria, by slight chemical modification of the protein with hydrophobic ligands throughtout thermal treatment. These modifications generate an amphitropic protein able to spread the cytoplasmic membrane (Vannini et al., 2004; Iucci et al., 2007). Peptic digestion or heat treatment are reported to augment the antimicrobial activity of lactoferrin. In this perspective, several authors tried to modify the enzyme structure, and 
consequently its activity, by using HPH in order to increase food safety. On the other hand the effect of HPH on naturally occurring food enzymes involved also in shelf-life, ripening and functionality of several matrices has been demonstrated (Kheadr et al., 2002; Lanciotti et al., 2004b, 2006; Vannini et al., 2008).

From a safety point of view, Vannini et al. (2004) evaluated the effect of HPH on the activity of antimicrobial enzymes such as lysozyme and lactoperoxidase against a selected group of Gram-positive and Gram-negative species inoculated in skim milk, formulating the hypothesis that the interaction of $\mathrm{HPH}$ and enzymes is associated to conformational modifications of the two proteins with a consequent enhancement of their activity. L. monocytogenes was the most pressure resistant species while S. typhimurium, $S$. aureus, and S. enteritidis were found to be very sensitive to the hyperbaric treatment. The enzyme addition enhanced the immediate pressure efficacy on almost all the considered species as indicated by their instantaneous viability loss following the treatment. Moreover, the combination of the enzyme and HPH significantly affected the recovery and growth dynamics of the considered species. Although L. monocytogenes was slightly sensitive to pressure, the combination of the two stress factors induced a significant viability loss within $3 \mathrm{~h}$ and an extension of lag phases in skim milk during incubation at $37^{\circ} \mathrm{C}$. Iucci et al. (2007) investigated the effects of $\mathrm{HPH}$ treatment at $100 \mathrm{MPa}$, in comparison to different heat treatments, $70^{\circ} \mathrm{C}$ for $30 \mathrm{~s}, 70^{\circ} \mathrm{C}$ for $5 \mathrm{~min}$ or $100^{\circ} \mathrm{C}$ for $5 \mathrm{~min}$, on the activity of lysozyme and lactoferrin. Their antimicrobial activities were tested on L. monocytogenes inoculated in milk or cultural medium. The results indicated that antimicrobial activities of lactoferrin and lysozyme were enhanced and/or accelerated by HPH treatment. Particularly, the highest immediate inactivation values were recorded when L. monocytogenes cells were added to HPHtreated lactoferrin, processed simultaneously or separately with the target microorganism. Although to a lesser extent than $\mathrm{HPH}$ treatment the heat treatments applied also were able to increase the antimicrobial activity of lysozyme. The Author suggested that the large supramolecular structure is disrupted under pressure, allowing the components to move freely and become independent of the original structure. Interactions can reform when the pressure instantaneously decreases but the original structure is not reformed because of the independent movements of the components.

Patrignani et al. (2013b) found for S. enteritidis, inoculated in LWE, HPH inactivation linearly correlated to the number of passes at $100 \mathrm{MPa}$ underling as for LWE, it is important to take into consideration the additional effect of HPH on the antimicrobial activity of naturally occurring enzymes, such as lysozyme. In fact, dynamic pressure is reported to enhance antimicrobial activity of lysozyme and lactoferrin, probably due to the change of the exposure of hydrophobic regions (Iucci et al., 2007). Guerzoni et al. (2002) hypothesized that the inactivation of $S$. enteritidis in egg based formulation treated at different $\mathrm{HPH}$ pressure and its inability to re grow in the system at $10^{\circ} \mathrm{C}$ was due to the increase of activity of HPH treated lysozyme from eggs. Also Velazquez-Estrada et al. (2008) attributed higher inactivation of S. enterica serovar Senftenberg 775Win HPH LWE to effects of pressure on cells and naturally occurring antimicrobial enzymes. Diels et al. (2005) observed that, above $150 \mathrm{MPa}$, E. coli became more sensitive to lysozyme when this compound was added before HPH treatment compared with adding the enzyme after the treatments, indicating that $\mathrm{HPH}$ treatment increases effectiveness and action spectrum of lysozyme.

\section{CONCLUSION}

The critical evaluation of the available literature data has showed the great potential of HPH for microbial inactivation and food safety purpose. Since 1990 several Authors have been tested its potentialities in vitro and real systems, demonstrating its different ability for pathogenic species inactivation in relation to the strains considered, the food matrix and technological procedures adopted. However, until the introduction of new valve design and ultra high pressure homogenizers, able to reach pressures of $400 \mathrm{MPa}$, this technology was implemented in food industry only for fat globule reduction, for juice treatment and emulsion creation. The introduction of these new variables have opened new field in food sector, also for food decontamination and permitting to replace or minimize the traditional thermal treatments generally applied for the safety purposes. The new main applications regard the treatment of milk (for consumption or dairy product manufacture), fruit and vegetable juice, vegetable milks, and food component (such as enzymes) obtaining more stable and safer products without detrimental effects on quality properties. In fact, in the most of the cases, the literature data have underlined an improvement of the sensory and nutritional properties and stability of the HPH and UHPH treated products. The replacement of traditional thermal treatment can represent an advantage for the industry since this $\mathrm{HPH}$ is a cold technology with a lower impact on the environment, more sustainable, saving energy, time and additional costs. Moreover the literature data have demonstrated that HPH, when applied to the milk for cheesemaking, can increase the cheese yield, reduce the cheese hydrolytic patterns, reducing the costs for ripening.

Moreover, another important improvement of the state of the art was done for the inactivation of resistant endospores, which still represent a great challenge for food industry. The literature data have pointed out that the combination of UHPH and several chemico-physical hurdles can be regarded as tool for spore inactivation especially for milk based products. Further improve of food safety and functional properties could be achieved exploiting the well recognized dynamic pressure potential to obtain nanoparticles of antimicrobial molecules or functional ingredients. However, also in this case the reduction of thermal treatment can represent an advantage for food industry and contribute to the maintenance of the quality and nutritional properties of foods.

However, although the achieved aims, UHPH has not been yet implemented in food industry since conventional and ultra 
homogenizer do not guarantee by themselves the sterilization and, subsequently, packaging of foods in aseptic conditions is needed. This results in a great disadvantage for food industry because it limits the implementation of this technology in food process as full alternative to thermal treatment.

\section{REFERENCES}

Amador Espejo, G. G., Hernandez-Herrero, M. M., Juan, B., and Trujillo, A. J. (2014). Inactivation of Bacillus spores inoculated in milk by Ultra High Pressure Homogenization. Food Microbiol 44, 204-210.

Bernkop-Schnurch, A., Krist, S., Vehabovic, M., and Valenta, C. (1998). Synthesis and evaluation of lysozyme derivates exhibiting an enhanced antimicrobial action. Euro. J. Pharm. Sci. 6, 301-306. doi: 10.1016/S0928-0987(97)10026-4

Betoret, E., Betoret, N., Rocculi, P., and Dalla Rosa, M. (2015). Strategies to improve food functionality: structure-property relationships on high pressures homogenization, vacuum impregnation and drying technologies. Trends Food Sci. Technol. 46, 1-12. doi: 10.1016/j.tifs.2015.07.006

Bevilacqua, A., Cibelli, F., Corbo, M. R., and Sinigaglia, M. (2007). Effects of highpressure homogenization on the survival of Alicyclobacillus acidoterrestris in a laboratory medium. Lett. App. Microbiol. 45, 382-386. doi: 10.1111/j.1472765X.2007.02219.x

Bevilacqua, A., Corbo, M. R., and Sinigaglia, M. (2012). High-pressure homogenisation and benzoate to control Alicyclobacillus acidoterrestris: a possible way? Int. J. Food Sci. Technol. 47, 879-883. doi: 10.1111/j.13652621.2011.02913.x

Bevilacqua, A., Costa, C., Corbo, M. R., and Sinigaglia, M. (2009). Effects of the high pressure of homogenization on some spoiling microorganisms, representative of fruit juice microflora, inoculated in saline solution. Lett. Appl. Microbiol. 48, 261-267. doi: 10.1111/j.1472-765X.2008.02527.x

Brinez, W. J., Roig-Sagues, A. X., Herrero, M. H., and Lopez, B. G. (2006a). Inactivation by ultra high-pressure homogenization of Escherichia coli strains inoculated into orange juice. J. Food Prot. 69, 984-989.

Brinez, W. J., Roig-Sagues, A. X., Herrero, M. H., and Lopez, B. G. (2006b). Inactivation of Listeria innocua in milk and orange juice by ultrahigh-pressure homogenization. J. Food Protect. 69, 86-92.

Brinez, W. J., Roig-Sagues, A. X., Herrero, M. H., and Lopez, B. G. (2007). Inactivation of Staphylococcus spp. strains in whole milk and orange juice using ultra high pressure homogenisation at inlet temperatures of 6 and 20 degrees ${ }^{\circ}$ C. Food Control 10, 1282-1288. doi: 10.1016/j.foodcont.2006. 09.002

Burns, B., Patrignani, F., Serrazanetti, D., Vinderola, G. C., Reinheimer, J. A., Lanciotti, R., et al. (2008). Probiotic crescenza cheese containing Lactobacillus casei and Lactobacillus acidophilus manufactured with high pressure-homogenized milk. J. Dairy Sci. 91, 500-512. doi: 10.3168/jds.20070516

Burns, P., Patrignani, F., Tabanelli, G., Vinderola, G. C., Siroli, L., Reinheimer, J. A., et al. (2015). Potential of high pressure homogenisation on probiotic Caciotta cheese quality and functionality. J. Funct. Foods 13, 126-136. doi: 10.1016/j.jff.2014.12.037

Burt, S. (2004). Essential oils: their antibacterial properties and potential applications in foods. Rev. J. Food Microbiol. 94, 223-253. doi: 10.1016/j.ijfoodmicro.2004.03.022

Chaves-López, C., Lanciotti, R., Serio, A., Paparella, A., Guerzoni, M. E., and Suzzi, G. (2009). Effect of high pressure homogenization applied individually or in combination with other mild physical or chemical stresses on Bacillus cereus and Bacillus subtilis spore viability. Food Control 20, 691-695. doi: 10.1016/j.foodcont.2008.09.001

Chen, W., Harte, F. M., Davidson, P. M., and Golden, D. A. (2013). Inactivation of Alicyclobacillus acidoterrestris using high pressure homogenization and dimethyl dicarbonate. J. Food Protect. 76, 1041-1045. doi: 10.4315/0362028X.JFP-12-443

Cortezzo, D. E., Setlow, B., and Setlow, P. (2004). Analysis of the action of compounds that inhibit the germination of spores of Bacillus species. J. Appl. Microbiol. 96, 725-741. doi: 10.1111/j.1365-2672.2004. 02196.x

\section{AUTHOR CONTRIBUTIONS}

FP and RL put in writing this review together consulting the available literature, patents on the topic and trying to investigate several aspects on high pressure homogenization and safety.

Diels, A. M., and Michiels, C. W. (2006). High-pressure homogenization as a nonthermal technique for the inactivation of microorganisms. Crit. Rev. Microbiol. 32, 201-216. doi: 10.1080/10408410601023516

Diels, A. M. J., Callewaert, L., Wuytack, E. Y., Masschalck, B., and Michiels, C. W. (2004). Moderate temperatures affect Escherichia coli inactivation by high-pressure homogenization only through fluid viscosity. Biotechnol. Prog. 20, 1512-1517. doi: 10.1021/bp0499092

Diels, A. M. J., Callewaert, L., Wuytack, E. Y., Masschalck, B., and Michiels, C. W. (2005). Inactivation of Escherichia coli by high-pressure homogenisation is influenced by fluid viscosity but not by water activity and product composition. Int. J. Food Microbiol. 101, 281-291. doi: 10.1016/j.ijfoodmicro.2004.11.011

Diels, A. M. J., Wuytack, E. Y., and Michiels, C. W. (2003). Modelling inactivation of Staphylococcus aureus and Yersinia enterocolitica by highpressure homogenisation at different temperatures. Int. J. Food Microbiol. 87, 55-62. doi: 10.1016/S0168-1605(03)00050-3

Dong, P., Georget, E. S., Aganovic, K., Heinz, V., and Mathys, A. (2015). Ultra high pressure homogenization (UHPH) inactivation of Bacillus amyloliquefaciens spores in phosphate buffered saline (PBS) and milk. Front. Microbiol. 6:712. doi: $10.3389 /$ fmicb. 2015.00712

Donsì, F., Ferrari, G., and Maresca, P. (2009a). "High-pressure homogenisation for food sanitisation," in Global Issues in Food Science and Technology, eds G. Barbosa-Cànovas, A. Mortimer, D. Lineback, W. Spiess, K. Buckle, and P. Colonna (Cambridge, MA: Academic Press), 309-352.

Donsì, F., Ferrari, G., and Maresca, P. (2009b). Main factors regulating microbial inactivation by high-pressure homogenization: operating parameters and scale of operation. Chem. Eng. Sci. 64, 520-532. doi: 10.1016/j.ces.2008.10.002

Donsì, F., Esposito, L., Lenza, E., Senatore, B., and Ferrari, G. (2009c). Production of shelf-stable annurca apple juice with pulp by high pressure homogenization. Int. J. Food Eng. 5:12. doi: 10.2202/1556-3758.1602

Dumay, E., Chevalier-Lucia, D., Picart-Palmade, L., Benzaria, A., Gràcia-Julià, A., and Blayo, C. (2013). Technological aspects and potential applications of (ultra) high-pressure homogenisation. Trends Food Sci. Technol. 31, 13-26. doi: 10.1016/j.tifs.2012.03.005

Ferragut, M., Hernández-Herrero, M., Veciana-Nogués, T., Borras-Suarez, M., González-Linares, J., Vidal-Caroub, M. C., et al. (2015). Ultra-high-pressure homogenization UHPH system for producing high-quality vegetable-based beverages: physicochemical, microbiological, nutritional and toxicological characteristics. J. Sci. Food Agric. 95, 953-961. doi: 10.1002/jsfa.6769

Floury, J., Bellettre, J., Legrand, J., and Desrumaux, A. (2004). Analysis of a new type of homogenizer. A study of the flown pattern. Chem. Eng. Sci. 59, 843-853. doi: 10.1016/j.ces.2003.11.017

Floury, J., Desrumaux, A., and Lardières, J. (2000). Effect of high-pressure homogenization on droplet size distributions and rheological properties of model oil-in-water emulsions. Innov. Food Sci. Emerg 1, 127-134. doi: 10.1016/S1466-8564(00)00012-6

Gaulin A. (1899). System for Intimately Mixing Milk. US 756953.

Georget, E., Miller, B., Aganovic, K., Callanan, M., Heinz, V., and Mathys, A. (2014a). Bacterial spore inactivation by ultra-high pressure homogenization. Innov. Food Sci. Emerg. Technol. 26, 116-123. doi: 10.1016/j.ifset.2014. 08.004

Georget, E., Miller, B., Callanan, M., Heinz, V., and Mathys, A. (2014b). (Ultra) high pressure homogenization for continuous high pressure sterilization of pumpable foods-a review. Front. Nutr. 1:15. doi: 10.3389/fnut.2014. 00015

Guerzoni, M. E., Lanciotti, R., Westall, F., and Pittia, P. (1997). Interrelationship between chemico-physical variables, microstructure and growth of Listeria monocytogenes and Yarrowia lipolytica in food model systems. Sci. Aliment. 17, 497-512.

Guerzoni, M. E., Vannini, L., Chaves Lopez, C., Lanciotti, R., Suzzi, G., and Gianotti, A. (1999). Effect of high pressure homogenization on microbial and 
chemico-physical characteristics of goat cheeses. J. Dairy Sci. 82, 851-862. doi: 10.3168/jds.S0022-0302(99)75303-8

Guerzoni, M. E., Vannini, L., Lanciotti, R., and Gardini, F. (2002). Optimisation of the formulation and of the technological process of egg-based products for the prevention of Salmonella enteritidis survival and growth. Int. J. Food Microbiol. 73, 367-374. doi: 10.1016/S0168-1605(01)00673-0

Hayes, M. G., Fox, P. F., and Kelly, A. L. (2005). Potential applications of high pressure homogenisation in processing of liquid milk. J. Dairy Res. 72, 25-33. doi: $10.1017 /$ S0022029904000524

Hayes, M. G., and Kelly, A. L. (2003). High pressure homogenisation of raw whole bovine milk (a) effects on fat globules size and other properties. J. Dairy Res. 70 , 297-305. doi: 10.1017/S0022029903006320

Ibrahim, H. R., Kato, A., and Kobayashi, K. (1993). Length of hydrocarbon chain and antimicrobial action to gram-negative of fatty acylated lysozyme. J. Agric. Food Chem. 41, 1164-1188. doi: 10.1021/jf00031a029

Iucci, L., Lanciotti, R., Huppertz, T., and Kelly, A. (2008). Plasmin activity in high-pressure-homogenised bovine milk. Milchwissenschaft 63, 68-70

Iucci, L., Patrignani, F., Vallicelli, M., Guerzoni, M. E., and Lanciotti, R. (2007). Effects of high pressure homogenization on the activity of lysozyme and lactoferrin against Listeria monocytogenes. Food Control 18, 558-565. doi: 10.1016/j.foodcont.2006.01.005

Keshavarz Moore, E., Hoare, M., and Dunnill, P. (1990). Disruption of baker's yeast in a high-pressure homogenizer: new evidence on mechanism. Enzyme Microb. Technol. 12, 764-770. doi: 10.1016/0141-0229(90)90149-K

Kheadr, E. E., Vachon, J. F., Paquin, P., and Fliss, I. (2002). Effect of dynamic pressure on microbiological, rheological and microstructural quality of Cheddar cheese. Int. Dairy J. 12, 435-446. doi: 10.1016/S0958-6946(01)00104-2

Kumar, S., Thippareddi, H., Subbiah, J., Zivanovic, S., Davidson, P. M., and Harte, F. (2009). Inactivation of Escherichia coli K-12 in apple juice using combination of high-pressure homogenization and chitosan. J. Food Sci. 74, M8-M14. doi: 10.1111/j.1750-3841.2008.00974.x

Lanciotti, R., Chaves-Lopez, C., Patrignani, F., Paparella, A., Guerzoni, M. E., Serio, A., et al. (2004b). Effects of milk treatment with dynamic high pressure on microbial population as well as on the lipolytic and proteolytic profiles of Crescenza cheese. Int. J. Dairy Technol. 57, 19-25. doi: 10.1111/j.14710307.2004.00121.x

Lanciotti, R., Gardini, F., Sinigaglia, M., and Guerzoni, M. E. (1996). Effects of growth conditions on the resistance of some pathogenic and spoilage species to high pressure homogenization. Lett. Appl. Microbiol. 22, 165-168. doi: 10.1111/j.1472-765X.1996.tb01134.x

Lanciotti, R., Patrignani, F., Iucci, L., Guerzoni, M. E., Suzzi, G., Belletti, N., et al. (2007a). Effects of milk high pressure homogenization on biogenic amine accumulation during ripening of ovine and bovine Italian cheeses. Food Chem. 104, 693-701. doi: 10.1016/j.foodchem.2006.12.017

Lanciotti, R., Patrignani, F., Iucci, L., Saracino, P., and Guerzoni, M. E. (2007b). Potential of high pressure homogenization in the control and enhancement of proteolytic and fermentative activities of some Lactobacillus species. Food Chem. 102, 542-550. doi: 10.1016/j.foodchem.2006.06.043

Lanciotti, R., Sinigaglia, M., Angelini, P., and Guerzoni, M. E. (1994). Effects of homogenization pressure on the survival and growth of some food spoilage and pathogenic micro-organisms. Lett. Appl. Microbiol. 18, 319-322. doi: 10.1111/j.1472-765X.1994.tb00878.x

Lanciotti, R., Vannini, L., Patrignani, F., Iucci, L., Vallicelli, M., Ndagijimana, M., et al. (2006). Effect of high pressure homogenisation of milk on cheese yield and microbiology, lipolysis and proteolysis during ripening of Caciotta cheese. J. Dairy Res 73, 216-226. doi: 10.1017/S0022029905001640

Lanciotti, R., Vannini, L., Pittia, P., and Guerzoni, M. E. (2004a). Suitability of high dynamic-pressure-treated milk for the production of yogurt. Food Microbiol. 21, 753-760. doi: 10.1016/j.fm.2004.01.014

Leistner, L. (2000). Basic aspects of food preservation by hurdle technology. Int. J. Food Microbiol. 55, 181-186. doi: 10.1016/S0168-1605(00)00161-6

López-Pedemonte, T., Brinez, W. J., Roig-Sagues, A. X., and Guamis, B. (2006). Fate of Staphylococcus aureus in cheese treated by ultrahigh pressure homogenization and high hydrostatic pressure. J. Dairy Sci. 89, 4536-4544. doi: 10.3168/jds.S0022-0302(06)72502-4

Maresca, P., Donsì, F., and Ferrari, G. (2011). Application of a multi-pass highpressure homogenization treatment for the pasteurization of fruit juices. J. Food Eng. 104, 364-372. doi: 10.1016/j.jfoodeng.2010.12.030
Muramalla, T., and Aryana, K. J. (2011). Some low homogenization pressures improve certain probiotic characteristics of yogurt culture bacteria and Lactobacillus acidophilus LA-K. J. Dairy Sci 94, 3725-3738. doi: 10.3168/jds.2010-3737

Navarro, J. L., Izquierdo, L., Carbonell, J. V., and Sentandreu, E. (2014). Effect of $\mathrm{pH}$, temperature and maturity on pectinmethylesterase inactivation of citrus juices treated by high-pressure homogenization. LWT-Food Sci. Technol. 57, 785-788. doi: 10.1016/j.lwt.2014.01.033

Panozzo, A., Manzocco, L., Calligaris, S., Bartolomeoli, I., Maifreni, M., Lippe, G., et al. (2014). Effect of high pressure homogenisation on microbial inactivation, protein structure and functionality of egg white. Food Res. Int. 62, 718-725. doi: 10.1016/j.foodres.2014.04.051

Pathanibul, P., Taylor, T. M., Davidson, P. M., and Harte, F. (2009). Inactivation of Escherichia coli and Listeria innocua in apple and carrot juices using high pressure homogenization and nisin. Int. J. Food Microbiol. 129, 316-320. doi: 10.1016/j.ijfoodmicro.2008.12.020

Patrignani, F., Burns, P., Serrazanetti, D., Vinderola, G., Reinheimer, J., Lanciotti, R., et al. (2009b). Suitability of high pressure-homogenized milk for the production of probiotic fermented milk containing Lactobacillus paracasei and Lactobacillus acidophilus. J. Dairy Res. 76, 74-82. doi: $10.1017 /$ S0022029908003828

Patrignani, F., Serrazanetti, D. I., Maina Mathara, J., Siroli, L., Gardini, F., Holzapfel, W. H., et al. (2015a). Use of homogenisation pressure to improve quality and functionality of probiotic fermented milks containing Lactobacillus rhamnosus BFE 5264. Int. J. Daity Technol. 60, 1-10. doi: 10.1111/14710307.12251

Patrignani, F., Siroli, L., Serrazanetti, D. I., Gardini, F., and Lanciotti, R. (2015b). Innovative strategies based on the use of essential oils and their components to improve safety, shelf-life and quality of minimally processed fruits and vegetables. Trends Food Sci. Technol. 46, 311-319. doi: 10.1016/j.tifs.2015.03.009

Patrignani, F., Tabanelli, G., Siroli, L., Gardini, F., and Lanciotti, R. (2013a). Combined effects of high pressure homogenization treatment and citral on microbiological quality of apricot juice. Int. J. Food Microbiol. 160, 273-281. doi: 10.1016/j.ijfoodmicro.2012.10.021

Patrignani, F., Vannini, L., Sado Kamdem, S. L., Hernando, I., Marco-Molés, R., Guerzoni, M. E., et al. (2013b). High pressure homogenization vs heat treatment: safety andfunctional properties of liquid whole egg. Food Microbiol 36, 63-69. doi: 10.1016/j.fm.2013.04.004

Patrignani, F., Vannini, L., Sado Kamdem, S. L., Lanciotti, R., and Guerzoni, M. E. (2009a). Effect of high pressure homogenization on Saccharomyces cerevisiae inactivation and physico-chemical features in apricot and carrot juices. Int. J. Food Microbiol. 136, 26-31. doi: 10.1016/j.ijfoodmicro.2009.09.021

Patrignani, F., Vannini, L., Sado Kamdem, S. L., Lanciotti, R., and Guerzoni, M. E. (2010). Potentialities of high-pressure homogenization to inactivate Zygosaccharomyces bailii in fruit juices. J. Food Sci. 75, M116. doi: 10.1111/j.1750-3841.2009.01508.x

Pereda, J., Ferragut, V., Quevedo, J. M., Guamis, B., and Trujillo, A. J. (2009). Heat damage evaluation in ultra-high pressure homogenized milk. Food Hydrocoll. 23, 1974-1979. doi: 10.1016/j.foodhyd.2009.02.010

Pinho, C. R. G., Franchi, M. A., Tribstm, A. A. L., and Cristianini, M. (2011). Effect of ultra high pressure homogenization on alkaline phosphatise and lactoperoxidase activity in raw skim milk. Procedia Food Sci. 1, 874-878. doi: 10.1016/j.profoo.2011.09.131

Reineke, K., Mathys, A., Heinzm, V., and Knorr, D. (2013). Mechanisms of endospore inactivation under high pressure. Trends Microbiol. 21, 296-304. doi: 10.1016/j.tim.2013.03.001

Roig-Sagues, A. X., Asto, E., Engers, I., and Hernandez-Herrero, M. M. (2015). Improving the efficiency of ultra-high pressure homogenization treatments to inactivate spores of Alicyclobacillus spp. in orange juice controlling the inlet temperature. LWT-Food Sci. Technol. 63, 866-871. doi: 10.1016/j.lwt.2015.04.056

Roig-Sagues, A. X., Velazques, R. M., Montealegre-Agramount, P., et al. (2009). Fat content increases of ultra-high pressure homogenization on Listeria monocytogenes in milk. J. Dairy Sci. 92, 5396-5402.

Ross, A. I. V., Griffiths, M. W., Mittal, G. S., and Deeth, H. C. (2003). Combining nonthermal technologies to control foodborne microorganisms. Int. J. Food Microbiol. 89, 125-138. doi: 10.1016/S0168-1605(03)00161-2 
Sandra, S., and Dalgleish, D. G. (2005). Effects of ultra-high-pressure homogenization and heating on structural properties of casein micelles in reconstituted skim milk powder. Int. Dairy J. 15, 1095-1104. doi: 10.1016/j.idairyj.2004.11.015

Schubert, W. W., and Beaudet, R. A. (2011). Determination of lethality rate constants and D-values for heat-resistant Bacillus spores ATCC 29669 exposed to dry heat from $125^{\circ} \mathrm{C}$ to $200^{\circ} \mathrm{C}$. Astrobiol. 11, 1-11. doi: 10.1089/ast.2010. 0502

Setlow, P. (2000). "Resistance of bacterial spores," in Bacterial Stress Responses, eds G. Storz and R. Hengge-Aronis (Washington, DC: American Society for Microbiology), 217-230.

Shirgaonkar, I. Z. S., Lothe, R. R., and Pandit, A. B. (1998). Commentson the mechanism of microbial cell disruption in high-pressure and high-speed devices. Biotechnol. Prog. 14, 657-660. doi: 10.1021/bp980052g

Siroli, L., Patrignani, F., Serrazanetti, D. I., Gardini, F., and Lanciotti, R. (2015). Innovative strategies based on the use of bio-control agents to improve the safety, shelf-life and quality of minimally processed fruits and vegetables. Trends Food Sci Technol. 46, 302-310. doi: 10.1016/j.tifs.2015. 04.014

Tabanelli, G., Burns, P., Patrignani, F., Gardini, F., Lanciotti, R., Reinheimer, J., et al. (2012). Effect of a non-lethal high pressure homogenization treatment on the in vivo response of probiotic lactobacilli. Food Microbiol. 32, 302-307. doi: 10.1016/j.fm.2012.07.004

Tabanelli, G., Patrignani, F., Gardini, F., Vinderola, C. G., Reinheimer, J. A., Grazia, L., et al. (2014). Effect of a sub-lethal high pressure homogenization treatment on the fatty acid membrane composition of probiotic lactobacilli. Lett. Appl. Microbiol. 58, 109-117. doi: 10.1111/lam.12164

Tabanelli, G., Patrignani, F., Vinderola, G. C., Reinheimer, J. A., Gardini, F., and Lanciotti, R. (2013). Effect of sub-lethal high pressure homogenization treatments on in vitro functional and biological properties of lactic acid bacteria. Food Sci. Technol 53, 580-586.

Tahiri, I., Makhlouf, J., Paquin, P., and Fliss, I. (2006). Inactivation of food spoilage bacteria and Escherichia coli $\mathrm{O} 157: \mathrm{H} 7$ in phosphate buffer and orange juice using dynamic high pressure. Food Res. Int. 39, 98-105. doi: 10.1016/j.foodres.2005.06.005

Tapia de Daza, M. S., Alzamora, S. M., and Chanes, J. W. (1996). Combination of preservation factors applied to minimal processing of foods. Crit. Rev. Food Sci. Nutr. 36, 629-659. doi: 10.1080/10408399609527742
Taylor, T. M., Roach, A., Black, D. G., Davidson, P. M., and Harte, F. (2007). Inactivation of Escherichia coli K-12 exposed to pressures in excess of $300 \mathrm{mpa}$ in a high-pressure homogenizer. J. Food Prot. 70, 1007-1010.

Vachon, J. F., Kheadr, E. E., Giasson, J., Paquin, P., and Fliss, I. (2002). Inactivation of foodborne pathogens in milk using dynamic high pressure. J. Food Prot. 65, 345-352.

Vannini, L., Lanciotti, R., Baldi, D., and Guerzoni, M. E. (2004). Interactions between high pressure homogenization and antimicrobial activity of lizozyme and lactoperoxidase. Int. J. Food Microbiol. 94, 123-135. doi: 10.1016/j.ijfoodmicro.2004.01.005

Vannini, L., Patrignani, F., Iucci, L., Ndagijimana, M., Lanciotti, R., vallicelli, M., et al. (2008). Effect of a pre-treatment of milk with high pressure homogenization on yield as well as on microbiological, lipolytic and proteolytic patterns of "Pecorino" cheese. Int. J. Food Microbiol. 128, 329-335.

Velazquez-Estrada, R. M., Hernandez-Herrero, M. M., Lopez-Pedemonte, T., Guamis-Lopez, B., and Roig Sagues, A. X. (2008). Inactivation of Salmonella enterica serovar senftenberg $775 \mathrm{~W}$ in liquid whole egg by ultrahigh pressure homogenization. J. Food Prot. 71, 2283-2288.

Wuytack, E. Y., Diels, A. J., and Michiels, C. W. (2002). Bacterial inactivation by high pressure homogenization and high hydrostatic pressure. Int. J. Food Microbiol. 77, 205-212. doi: 10.1016/S0168-1605(02)00054-5

Zamora, A., and Guamis, B. (2015). Opportunities for ultra-high-pressure homogenisation (UHPH) for the food industry. Food. Eng. Rev. 7, 130-142. doi: 10.1007/s12393-014-9097-4

Zhao, L., Wang, Y., Wang, S., Li, H., Huang, W., and Liao, X. (2014). Inactivation of naturally occurring microbiota in cucumber juice by pressure treatment. Int. J. Food Microbiol. 174, 12-18. doi: 10.1016/j.ijfoodmicro.2013.12.023

Conflict of Interest Statement: The authors declare that the research was conducted in the absence of any commercial or financial relationships that could be construed as a potential conflict of interest.

Copyright $\odot 2016$ Patrignani and Lanciotti. This is an open-access article distributed under the terms of the Creative Commons Attribution License (CC BY). The use, distribution or reproduction in other forums is permitted, provided the original author(s) or licensor are credited and that the original publication in this journal is cited, in accordance with accepted academic practice. No use, distribution or reproduction is permitted which does not comply with these terms. 